\title{
INCAPACIDAD TEMPORAL Y DESPIDO. A PROPÓSITO DE UNA SENTENCIA DEL TRIBUNAL DEL JUSTICIA DE LA UNIÓN EUROPEA DE 1 DE DICIEMBRE DE 2016, ASUNTO DAOUIDI, C-395/15
}

\author{
LARA M. MUNÍN SÁNCHEZ \\ Juez sustituta \\ Doctora en Derecho \\ Profesora Asociada de la Facultad de Ciencias del Trabajo \\ Universidade da Coruña
}

\begin{abstract}
Resumen: La jurisprudencia del Tribunal de Justicia de la Unión Europea tiene una gran importancia tanto la evolución de nuestras instituciones jurídico - laborales como en su interpretación conforme al derecho comunitario. La cuestión presente concierne a la calificación como discriminatoria de los despidos de trabajadores que se encuentran enfermos o de baja, lo que supone un cambio jurisprudencial en relación a lo que había sido el tradicional criterio del Tribunal Supremo español, que ha descartado de manera sistemática su calificación como nulos. Ahora, la respuesta no es tan sencilla, sino que habrá que analizar caso por caso la duración de la baja, la gravedad de la dolencia y el propio conocimiento que sobre la incapacidad tiene el empresario.
\end{abstract}

Palabras clave: Incapacidad temporal - Despido - Discriminación - Enfermedad

\begin{abstract}
The jurisprudence of the Court of Justice of the European Union has a great importance both the evolution of our institutions legal - labour as in its interpretation in conformity with Community law. The present issue concerns qualify as discriminatory those dismissals of employees who are ill or time off sick. That's a jurisprudential change in relation to what had been the traditional criterion of the Spanish Supreme Court, which has ruled out in a systematic manner their qualification as null. Now, the answer is not so simple, but it will be analyzed case by case the duration of the time off sick, the disease's seriousness and the employer's own knowledge about it.
\end{abstract}

Keywords: Temporary disability - Dismissal - Discrimination - Illness 
1. En la Sentencia de Tribunal de Justicia de la Unión Europea, que se va a analizar y que lleva por fecha el 1 de diciembre de 2016, asunto Daouidi, C-385/15 ${ }^{1}$ se procede a analizar, una cuestión prejudicial planteada por el Juzgado de lo Social núm. 33 de Barcelona, al hilo de un despido de un trabajador que se encontraba en incapacidad temporal $^{2}$, y es la posibilidad de que dicha decisión extintiva pueda proscribirse en base a la igualdad de trato en el empleo y la ocupación conforme a la Directiva 2000/78/CEE, del Consejo, de 27 de noviembre de 2000, relativa al establecimiento de un marco general para la igualdad de trato en el empleo y la ocupación (DO 2000, L 303 , p. 16), porque -en esta importante decisión- se ha procedido a equiparar -bajo determinados presupuestos- la incapacidad a la discapacidad, sobre la base de una serie de datos objetivos, para concluir que dicho despido será discriminatorio en el caso de que la perspectiva de curación no sea a corto plazo o pueda prolongarse indefinidamente. El marco fáctico sobre el que se produce la decisión es el siguiente ${ }^{3}$ : (a) el Sr. Daouidi fue contratado por una empresa llamada Bootes Plus para trabajar como ayudante de cocina en uno de los restaurantes de un hotel situado en Barcelona; (b) el contrato fue eventual a tiempo parcial inicialmente, pero transformado en a tiempo completo; (c) el 3 de octubre de 2014, el Sr. Daouidi resbaló en la cocina del restaurante en el que trabajaba, lo que le dislocó el codo izquierdo, que tuvo que ser enyesado y, en esa misma fecha, inició el proceso para que se le reconociera una incapacidad temporal derivada de accidente laboral; (d) a las dos semanas de ese accidente laboral, su jefe contactó con el trabajador accidentado para interesarse sobre su estado de salud y previsible duración de su baja, indicándole el trabajador que su reincorporación no podía ser inmediata; (e) el 26 de noviembre de 2014, estando aún en situación de incapacidad temporal, el Sr. Daouidi recibió de Bootes Plus una carta de despido; (f) el 23 de diciembre de 2014, el trabajador presentó demanda ante el Juzgado de lo Social núm. 33 de Barcelona, cuya pretensión principal es que se declare la nulidad de su despido, bajo la alegación de que esta medida, al tener por causa o motivo real su situación de incapacidad temporal derivada de su accidente de trabajo, es discriminatorio y guarda relación, por tanto, con el concepto de «discapacidad» con arreglo a la Directiva 2000/78 y a la sentencia de 11 de abril de 2013, HK Danmark (C335/11 y C-337/11); (g) el Juzgado cree que se han acreditado datos suficientes para considerar que, aunque el despido lo es con formalidad y apariencia disciplinaria, su motivo real es la situación de incapacidad — de duración incierta- derivada del accidente laboral, y, sin embargo, la jurisprudencia del Tribunal Superior de Justicia de Cataluña, del Tribunal Supremo y del Tribunal Constitucional no podría considerarse

\footnotetext{
${ }^{1}$ Accesible en el link:

http://curia.europa.eu/juris/document/document.jsf;jsessionid=9ea7d0f130d5826c00ae72ee490e9a889db3 a68bd6d5.e34KaxiLc3eQc40LaxqMbN4PaxuMe0?text=\&docid=185743\&pageIndex=0\&doclang=es\&m ode $=1$ st $\&$ dir $=\&$ occ $=$ first $\&$ part $=1 \&$ cid $=868197$.

2 «1. Tendrán la consideración de situaciones determinantes de incapacidad temporal: a) Las debidas a enfermedad común o profesional y a accidente, sea o no de trabajo, mientras el trabajador reciba asistencia sanitaria de la Seguridad Social y esté impedido para el trabajo, con una duración máxima de trescientos sesenta y cinco días, prorrogables por otros ciento ochenta días cuando se presuma que durante ellos puede el trabajador ser dado de alta médica por curación. b) Los períodos de observación por enfermedad profesional en los que se prescriba la baja en el trabajo durante los mismos, con una duración máxima de seis meses, prorrogables por otros seis cuando se estime necesario para el estudio y diagnóstico de la enfermedad» (art. 169.1 Real Decreto Legislativo 8/2015, de 30 de octubre, por el que se aprueba el texto refundido de la Ley General de la Seguridad Social).

${ }^{3}$ Apartados 22 a 36.
} 
discriminatorio, sino improcedente; (h) por Auto del Juzgado de 14 de julio de 2015 se plantean una serie de cuestiones prejudiciales ante el Tribunal de Justicia de la Unión Europea; e (i) la Sentencia de Tribunal de Justicia de la Unión Europea de 1 de diciembre de 2016 responde a las cuestiones con el siguiente fallo «La Directiva 2000/78/CE del Consejo, de 27 de noviembre de 2000, relativa al establecimiento de un marco general para la igualdad de trato en el empleo y la ocupación, debe interpretarse en el sentido de que: - El hecho de que el interesado se halle en situación de incapacidad temporal, con arreglo al Derecho nacional, de duración incierta, a causa de un accidente laboral no significa, por sí solo, que la limitación de su capacidad pueda ser calificada de «duradera», con arreglo a la definición de «discapacidad» mencionada por esa Directiva, interpretada a la luz de la Convención de las Naciones Unidas sobre los derechos de las personas con discapacidad, aprobada en nombre de la Comunidad Europea por la Decisión 2010/48/CE del Consejo, de 26 de noviembre de 2009. - Entre los indicios que permiten considerar que tal limitación es «duradera» figuran, en particular, el que, en la fecha del hecho presuntamente discriminatorio, la incapacidad del interesado no presente una perspectiva bien delimitada en cuanto a su finalización a corto plazo o el que dicha incapacidad pueda prolongarse significativamente antes del restablecimiento de dicha persona. - Al comprobar ese carácter «duradero», el juzgado remitente debe basarse en todos los elementos objetivos de que disponga, en particular, en documentos y certificados relativos al estado de dicha persona, redactados de los conocimientos y datos médicos y científicos actuales».

Como complemento de lo anterior, se podría añadir - para conocer el iter procesal completo del asunto de fondo- que, tras recibirse la Sentencia de Tribunal de Justicia de la Unión Europea, el Juzgado de lo Social requirente dicta su Sentencia en fecha 23 de diciembre de 2016, Autos 1291/2014, en la que estima la nulidad del despido del trabajador por discriminatorio; sin embargo, recurrida en suplicación, la Sentencia del Tribunal Superior de Justicia de Cataluña de 12 de junio de 2017 -Recurso núm. 2310/17- revoca dicha resolución y, estimando el recurso planteado por la empleadora, rechaza la nulidad y aprecia únicamente la improcedencia, basándose en el escaso tiempo transcurrido desde el inicio de la incapacidad temporal hasta la fecha del despido y en la doctrina tradicional del Tribunal Supremo.

2. La fundamentación jurídica parte de la cuestión de si el estado del Sr. Daouidi, despedido mientras se hallaba en situación de incapacidad temporal, con arreglo al Derecho nacional, de duración incierta, está comprendido en el concepto de «discapacidad» en el sentido de la Directiva 2000/78 citada, que tiene por objeto establecer un marco general para luchar, en el ámbito del empleo y la ocupación, contra las discriminaciones basadas en cualquiera de los motivos mencionados en dicho artículo, entre los que está la discapacidad. De conformidad con su artículo 3, apartado 1, letra c), dicha Directiva se aplicará, dentro del límite de las competencias conferidas a la Unión Europea, a todas las personas, por lo que respecta tanto al sector público como al privado, en relación, en particular, con las condiciones de despido. Y, además, la Unión aprobó la Convención de la ONU sobre la discapacidad mediante la Decisión 2010/48, por lo que, a partir de la entrada en vigor de aquélla, sus disposiciones forman parte integrante del ordenamiento jurídico de la Unión ${ }^{4}$. Esto supone que dicha Convención puede ser invocada para interpretar esta Directiva, que en la medida de lo

\footnotetext{
${ }^{4}$ Véase la Sentencia de Tribunal de Justicia de la Unión Europea de 18 de marzo de 2014, C-363/12, apartado 73 y jurisprudencia citada.
} 
posible debe interpretarse de conformidad con esa misma Convención ${ }^{5}$. Todo lo cual conduce a que el concepto de «discapacidad» en el sentido de la Directiva 2000/78 debe entenderse como referido a una limitación, derivada en particular de dolencias físicas, mentales o psíquicas, a largo plazo, que, al interactuar con diversas barreras, puede impedir la participación plena y efectiva de la persona de que se trate en la vida profesional en igualdad de condiciones con los demás trabajadores ${ }^{6}$; y ello atañe también a las discapacidades debidas a accidentes ${ }^{7}$. En definitiva, hay que analizar si la limitación de la capacidad, que, al interactuar con diversas barreras, puede impedir la participación plena y efectiva del interesado en la vida profesional en igualdad de condiciones con los demás trabajadores, es «duradera» en el sentido anterior.

Éste es la premisa esencial, puesto que el Juzgado de instancia deberá comprobar si la limitación de la capacidad del interesado tiene ese carácter «duradero», ya que tal apreciación es, ante todo, de carácter fáctico, deducible de las circunstancias concurrentes a cada caso concreto. Entre los indicios que permiten considerar que una limitación es «duradera» figuran, en particular, el que, en la fecha del hecho presuntamente discriminatorio (despido o cualquier otra actuación), la incapacidad del interesado no presente una perspectiva bien delimitada en cuanto a su finalización a corto plazo o el que pueda prolongarse significativamente antes del restablecimiento de dicha persona. En esta prueba de indicios, el órgano juzgador debe basarse en todos los elementos objetivos de que se disponga, especialmente, en documentos y certificados relativos al estado de esa persona, redactados de acuerdo con los conocimientos y datos médicos y científicos actuales. Y, en el caso de que se llegase a la conclusión de que la limitación de la capacidad del despedido es «duradera», hay que recordar que un trato desfavorable por motivos de discapacidad sólo choca con la protección que pretende la Directiva 2000/78 en la medida en que constituya una discriminación con arreglo al artículo 2, apartado 1, de la misma Directiva ${ }^{8}$.

3. La decisión del alto tribunal comunitario tiene una gran importancia práctica, pese a que, en el caso concreto, se haya revocado la decisión tomada con posterioridad por el Juzgado -por parte del Tribunal Superior de Justicia-, en la que entendía que el despido era nulo, y, al final, su calificación no haya pasado de improcedente, basándose en la limitada duración de la baja y en la doctrina tradicional española. Es -precisamenteeste último punto donde se pueden extraer las conclusiones más importantes, porque ha venido a enmendar la jurisprudencia española, tanto ordinaria como constitucional, sobre la incapacidad, dado que, si bien el despido de los trabajadores con diversidad funcional se entiende nulo, salvo justificación, la de los incapacitados temporales es -en principio- improcedente ${ }^{9}$. El argumento es antiguo y reside en la idea de que, a diferencia de una incapacidad temporal, «cuando el factor enfermedad sea tomado en

\footnotetext{
${ }^{5}$ Véanse las Sentencias de Tribunal de Justicia de la Unión Europea de 11 de abril de 2013, HK Danmark, C-335/11 y C-337/11, apartado 32, y de 18 de marzo de 2014, C-363/12, apartado 75. ${ }^{6}$ Ídem.

${ }^{7}$ Véase, en este sentido, la Sentencia de Tribunal de Justicia de la Unión Europea de 11 de abril de 2013, HK Danmark, C-335/11 y C-337/11, apartado 40.

${ }^{8}$ Véanse las Sentencia de Tribunal de Justicia de la Unión Europea de 11 de julio de 2006, Chacón Navas, C-13/05, apartado 48, y de 11 de abril de 2013, HK Danmark, C-335/11 y C-337/11, apartado 71. ${ }^{9}$ Sobre esta doctrina se han producido críticas diversas; para todas, véase CARRIZOSA PRIETO, E., «Despido por incapacidad temporal: ¿discriminación por enfermedad o represalia por el ejercicio de un derecho fundamental? Sentencia del Tribunal Supremo, Sala de lo Social, de 18 de diciembre de 2007», en Temas Laborales: Revista andaluza de trabajo y bienestar social, núm. 96, 2008, págs. 267 y ss.
} 
consideración como un elemento de segregación basado en la mera existencia de la enfermedad en sí misma considerada o en la estigmatización como persona enferma de quien la padece, al margen de cualquier consideración que permita poner en relación dicha circunstancia con la aptitud del trabajador para desarrollar el contenido de la prestación laboral objeto del contrato», en tales circunstancias la decisión disciplinaria de un enfermo puede «constituir un factor de discriminación análogo a los expresamente contemplados en el art. $14 \mathrm{CE}$, encuadrable en la cláusula genérica de las otras circunstancias o condiciones personales o sociales contemplada en el mismo» ${ }^{10}$. En definitiva, el despido de un enfermo es calificado como improcedente, pero no como nulo ${ }^{11}$, porque «se confunden dos principios constitucionales -el principio de igualdad de trato y la tutela antidiscriminatoria- que tienen un distinto alcance [se citan las SSTS 17/10/90 Ar. 7929; 23/09/93 Ar. 7032; y 17/05/00 Ar. 5513) [...] [y] la referencia del inciso final del artículo 14 de la Constitución no puede interpretarse en el sentido de que comprenda cualquier tipo de condición o de circunstancia, pues en ese caso la prohibición de discriminación se confundiría con el principio de igualdad de trato afirmado de forma absoluta. Lo que caracteriza la prohibición de discriminación [...], es [...] que en ella se utiliza un factor de diferenciación que merece especial rechazo por el ordenamiento [...], porque para establecer la diferencia de trato se toman en consideración condiciones que históricamente han estado ligadas a formas de opresión o de segregación de determinados grupos de personas o que se excluyen como elementos de diferenciación para asegurar la plena eficacia de los valores constitucionales en que se funda la convivencia en una sociedad democrática y pluralista. La enfermedad, [...] desde una perspectiva estrictamente funcional de incapacidad para el trabajo, [...], no es un factor discriminatorio en el sentido estricto [...], aunque pudiera serlo en otras circunstancias en las que resulte apreciable el elemento de segregación. [...]. Tampoco resulta aquí aplicable la garantía del artículo 4.2.c). $2^{\circ}$ del Estatuto de los Trabajadores, porque ni consta que el actor haya sido declarado minusválido, ni el despido se ha producido en atención a una minusvalía sin repercusión en la aptitud para el trabajo, sino en atención a los períodos de baja en el trabajo y la consiguiente pérdida para la empresa de interés productivo en el trabajador» ${ }^{12}$.

En otras ocasiones, se ha sostenido que «manteniendo la premisa de que el derecho fundamental a no ser discriminado ha de guardar relación con criterios históricos de opresión o segregación, debemos reiterar aquí que la enfermedad "en sentido genérico", "desde una perspectiva estrictamente funcional de incapacidad para el trabajo", no puede ser considerada en principio como un motivo o "factor discriminatorio" en el ámbito del contrato de trabajo (STS 29-1-2001, citada). Se trata, por una parte, de una contingencia inherente a la condición humana y no específica de un grupo o colectivo

\footnotetext{
${ }^{10}$ Son palabras de la Sentencia del Tribunal Constitucional 62/2008, en su fundamento jurídico 6. Esta decisión fue objeto de amplios comentarios, que pueden consultarse en MONTOYA MELGAR, A., «¿Es discriminatorio el despido de un trabajador enfermo? Comentario a la STC 62/2008, de 26 de mayo», en Revista Española de Derecho del Trabajo, núm. 143, 2009, págs. 711 y ss.; y en RODRÍGUEZ PIÑERO Y BRAVO FERRER, M. «Despido por enfermedad y discriminación», en Relaciones Laborales, núm. 20, 2008, págs. 1 y ss.

${ }^{11}$ Reiterando precedentes las Sentencias del Tribunal Supremo de noviembre de 1993 -Repertorio de Jurisprudencia Aranzadi núm. 8346-; 19 de enero de 1994 -Repertorio de Jurisprudencia Aranzadi núm. 352-; 23 de mayo de 1996 -Repertorio de Jurisprudencia Aranzadi núm. 4612-; 30 de diciembre de 1997 -Repertorio de Jurisprudencia Aranzadi núm. 1998/447-.

${ }^{12}$ Son palabras de las Sentencias del Tribunal Supremo de 29 de enero de 2001 -Repertorio de Jurisprudencia Aranzadi núm. 2069-; 23 de septiembre de 2002 -Repertorio de Jurisprudencia Aranzadi núm. 449-; y 12 de julio de 2004 -Repertorio de Jurisprudencia Aranzadi núm. 7075-.
} 
de personas o de trabajadores. Se trata, además, de una situación cuyo acaecimiento puede determinar, cuando se produce con frecuencia inusitada, que "el mantenimiento del contrato de trabajo no se considere rentable por parte de la empresa" (STS 29-12001, citada). De ahí que, si el empresario decide despedir al trabajador afectado, podría ciertamente incurrir en conducta ilícita, si no demuestra la concurrencia de la causa de despido prevista en el arto 52.d) ET, pero no en una actuación viciada de nulidad radical por discriminación» ${ }^{13}$.

Tampoco la indemnidad del trabajador enfermo puede derivar del «derecho a la salud consagrado en el art. $15 \mathrm{CE}$ », puesto que confunde el derecho a la integridad física regulada por el artículo 15 de la Constitución Española- con el derecho a la protección de la salud -regulado por el artículo 43 de la misma- ${ }^{14}$, este planteamiento «parte de un erróneo presupuesto, cual es la "inaceptable asimilación" del derecho fundamental a la vida y a la integridad física [art. $15 \mathrm{CE}$ ] con el derecho a la protección de la salud [el art. 43.1 CE], pues sin perjuicio de la indudable conexión entre ambos derechos, el último de los citados no es un derecho fundamental, sino un principio rector de la política social y económica, y que como tal puede ser alegado ante la jurisdicción ordinaria de acuerdo con lo que dispongan las Leyes que lo desarrollen [art. 53.3 CE], pero no puede ser objeto de la tutela extraordinaria que para determinados derechos fundamentales otorga la Ley (ATC 57/07, de 26/Febrero, FJ 3). El invocado derecho a la integridad física protege ante todo la incolumidad corporal, esto es, el derecho de la persona "a no sufrir lesión o menoscabo en su cuerpo o en su apariencia externa sin su consentimiento" (SSTC 207/1996, de 16/Diciembre, FJ 2; 220/05, de 12/Septiembre, FJ 4); lo que únicamente guarda relación incidental con el supuesto de autos, en el que está en juego no el derecho a que no se dañe o perjudique la salud personal [intocados por el despido, ciertamente], sino más bien el derecho al trabajo -incluso en situaciones de infortunio físico- [art.35 CE]» (STS 22/11/07 -rcud 3907/06- LFDCF) ${ }^{15}$. «Sólo en determinados supuestos, por ejemplo el de enfermedades derivadas del embarazo que están ligadas a la condición de mujer, puede el despido por enfermedad o baja médica ser calificado como despido discriminatorio, viciado de nulidad. Pero se trata, en realidad, como ha declarado recientemente el Tribunal Constitucional (STC 17/2007, de 12/Febrero), de un supuesto particular de despido discriminatorio por razón de sexo, en cuanto que la decisión o práctica de la empresa de dar por terminado el contrato de trabajo por motivo concerniente al estado de gestación sólo puede afectar a las mujeres, situándolas en posición de desventaja con respecto a los hombres» ${ }^{16}$.

$\mathrm{Y}$, finalmente, tampoco cabe identificar enfermedad con discapacidad, para alcanzar la protección que le brindan el artículo 4.2.c) ET [redacción dada por la Ley 62/2003] y la Directiva comunitaria 2000/78, por tratarse de conceptos diferentes, como ha recordado la Sentencia de Tribunal de Justicia de la Unión Europea 11 de julio de 2006, Asunto Chacón Navas ${ }^{17}$. De esta forma, si «no se ha acreditado que el móvil del despido haya

\footnotetext{
${ }^{13}$ Son palabras de la Sentencia del Tribunal Supremo de 11 de diciembre de 2007 -Recurso de Casación para la unificación de doctrina núm. 4355/2006-.

${ }^{14}$ Véanse las Sentencias del Tribunal Supremo de 22 de noviembre de 2007 -Recurso de Casación para la unificación de doctrina núm. 3907/2006-; y de 22 de septiembre de 2008 -Recurso de Casación para la unificación de doctrina núm. 3591/2006-.

${ }^{15}$ Ídem.

${ }^{16}$ Véanse las Sentencias del Tribunal Supremo de 11 de diciembre de 2007 -Recurso de Casación para la unificación de doctrina núm. 4355/2006-; y del Tribunal Constitucional 74/2008, de 23 de junio, F. 2.

${ }^{17}$ Véanse las Sentencias del Tribunal Supremo de 22 de noviembre de 2007 -Recurso de Casación para la unificación de doctrina núm. 3907/06-; 11 de diciembre 2007 -Recurso de Casación para la unificación
} 
sido otro que la inevitable repercusión negativa en el rendimiento laboral de las enfermedades o bajas médicas del trabajador, un móvil que en esta litis determina la ilicitud e improcedencia del despido pero no la nulidad del mismo por discriminación o lesión de derechos fundamentales» ${ }^{18}$.

Es esta una línea jurisprudencial que se sigue manteniendo y que podría verse afectado por la Sentencia de Tribunal de Justicia de la Unión Europea que se está comentado, porque recientemente se reitera que «la enfermedad, sin adjetivos o cualificaciones adicionales, es una situación contingente de mera alteración de la salud, que puede y suele afectar por más o menos tiempo a la capacidad de trabajo del afectado. Como es de experiencia común, el colectivo de trabajadores enfermos en un lugar o momento determinados es un grupo de los llamados efímeros o de composición variable en el tiempo. La discapacidad es, en cambio, una situación permanente de minusvalía física, psíquica o sensorial, que altera de manera permanente las condiciones de vida de la persona discapacitada. En concreto, en el ordenamiento español la discapacidad es considerada como un 'estatus' que se reconoce oficialmente mediante una determinada declaración administrativa, la cual tiene validez por tiempo indefinido. Parece claro, a la vista de las indicaciones anteriores, que las razones que justifican la tutela legal antidiscriminatoria de los discapacitados en el ámbito de las relaciones de trabajo no concurren en las personas afectadas por enfermedades o dolencias simples. Estos enfermos necesitan curarse lo mejor y a la mayor brevedad posible. Los discapacitados o aquejados de una minusvalía permanente, que constituyen por ello un grupo o colectivo de personas de composición estable, tienen en cambio, como miembros de tal grupo o colectividad, unos objetivos y unas necesidades particulares de integración laboral y social que no se dan en las restantes dolencias o enfermedades» ${ }^{19}$.

4. No obstante y como colofón a lo expresado hasta ahora, la línea doctrinal comunitaria y la española confluyen en cierto sentido, porque en el despido del enfermo se plantean dos grandes interrogantes ${ }^{20}$, por una parte, determinar cuándo hay discapacidad y, por otra, cuándo hay discriminación por este motivo. Lo que ocurre es que si en relación al primero la doctrina del Tribunal de Justicia de la Unión Europea no contradice la del Tribunal Supremo, porque la enfermedad «sin cualificaciones adicionales» no constituye un factor de discriminación ni puede equipararse a la discapacidad; en relación al segundo sí ha habido desajustes en los conceptos de discapacidad que se han venido manteniendo, pues el Tribunal Supremo emplea uno restrictivo de discapacidad, exigiendo la existencia de «una situación de minusvalía permanente» que altera también «de manera permanente las condiciones de vida de la persona». Por lo tanto, la alteración que se produce es la equiparación de las bajas duraderas a la discapacidad a los efectos de entender que el despido es nulo, con la consiguiente inversión de la carga de la prueba sobre los procesos que se pudiesen producir con posterioridad; aparte de que esa durabilidad se deduce bien de una ausencia de una perspectiva de finalización a

\footnotetext{
de doctrina núm. 4355/2006-; y 22 de septiembre de 2008 -Recurso de Casación para la unificación de doctrina núm. 3591/2006-.

${ }^{18}$ Véanse las Sentencia del Tribunal Supremo de 11 de diciembre de 2007 -Recurso de Casación para la unificación de doctrina núm. 4355/2006-; y 22 de septiembre de 2008 -Recurso de Casación para la unificación de doctrina núm. 3591/2006-.

${ }^{19}$ Son palabras de la Sentencia del Tribunal Supremo de 3 de mayo de 2016 -Recurso de Casación para la unificación de doctrina núm. 3348/2014-

${ }^{20}$ Véase DESDENTADO DAROCA, E., «El despido del enfermo y la STJUE de 1 de diciembre de 2016 dictada en el caso Daouidi. Algunas reflexiones críticas», en Revista de Información Laboral, núm. 3, 2017, consultado a través de la base de datos Westlaw (BIB 2017/1107)
} 
corto plazo o una prolongación en el tiempo significativa. En otras palabras, frente a la postura judicial española tradicional (incapacidad temporal excluye, en principio, la nulidad), ahora deberá analizarse cuál es la duración de la situación temporal por si resultase equiparable a una discapacidad (incapacidad permanente).

Es más, tal y como ha sostenido algún autor ${ }^{21}$, tres son -en definitiva- las hipótesis en las que se podría sostener la nulidad del despido de un incapacitado temporal: la primera cuando el despido se produce con un efecto estigmatizador del padecimiento de determinadas enfermedades que provocan rechazo social, ${ }^{22}$ con infracción del derecho constitucional de igualdad (artículo 14 de la Constitución Española). La segunda, cuando se presiona al trabajador para que se reincorpore instando el alta médica voluntaria, bajo amenaza de despido, entendiéndose que esta conducta pone en riesgo la salud y resulta lesiva para la integridad física ${ }^{23}$. Y, la tercera, que se desprende de la doctrina Ring $^{24}$ y ahora de doctrina Daouidi ${ }^{25}$, es el desarrollo del concepto de «enfermedad equiparable a discapacidad» que tiene su apoyo en la Directiva 2000/78/CE.

\footnotetext{
${ }^{21}$ Véase SÁNCHEZ PÉREZ, J., «El despido del trabajador en situación de incapacidad temporal: el derecho al rendimiento empresarial frente al derecho de protección de la salud», en Revista de Información Laboral, núm. 5, 2017, consultado a través de la base de datos Westlaw (BIB 2017/11172). ${ }^{22}$ Véase la Sentencia del Tribunal Constitucional 62/2008, de 26/mayo

${ }^{23}$ Cfr. MORENO MÁRQUEZ, A., «Nulidad del despido en los casos de reincorporación forzada del trabajador en incapacidad temporal: el derecho a la salud en juego», en Aranzadi Social, núm. 11, 2010, págs. 1 y ss.

${ }^{24}$ Véase la Sentencia de Tribunal de Justicia de la Unión Europea de 11 de abril de 2013, asunto HK, C$335 / 11$ y C-337/11.

${ }^{25}$ Sentencia que se comenta en este artículo.
} 